\title{
Willpower building: a new element in relapse prevention
}

\begin{abstract}
Willpower, self-control and self-regulation may be important ingredients in recovering from addiction. The authors contend that findings from controlled experiments into self-control and self-regulation can be usefully translated into clinical practice as part of a relapse prevention programme. This would be in the form of willpower building, with willpower being broadly synonymous with self-control and self-regulation. Numerous studies indicate that self-control is a capacity which functions like a muscle. In this sense, self-control can be built up, but is also subject to depletion when utilised. Findings suggest that there is direct applicability for self-control in relation to addiction, and recovery in general. It is possible that this capacity
\end{abstract}

can be developed through individual or group sessions. It is argued that clinical sessions should focus on: awareness, planning, building protective habits and exercising self-regulation. While some of these areas are covered in traditional psychological treatments of addiction (i.e., Cognitive Behaviour Therapy and Motivational Interviewing), making this capacity more explicit would be advantageous. Our challenge is for researchers to test these notions in controlled clinical studies.

\section{KEY WORDS}

willpower; self-control; self-regulation; addiction; relapse prevention; CBT

ORGANIZATION - 1: Central and North West London NHS Foundation Trust, United Kingdom · 2: Cambridgeshire and Peterborough NHS Foundation Trust, United Kingdom

authors' Contributions - A: Study design - B: Data collection - C: Statistical analysis - D: Data interpretation . E: Manuscript preparation · F: Literature search · G: Funds collection

CORRESPONDING AUTHOR - Ryan Kemp, Ph.D., Central and North West London NHS Foundation Trust, MK Community Services HQ, Hospital Campus, MK6 5NG Milton Keynes, United Kingdom, e-mail: ryan.kemp@nhs.net

TO CITE THIS ARTICLE - Kemp, R., Channer, K., \& Zahn, A. (2016). Willpower building: a new element in relapse

prevention. Health Psychology Report, 4(4), 281-286. doi: 10.5114/hpr.2016.59887

RECEIVED 21.02.2016 · REVIEWED 17.03.2016 · ACCEPTED 21.04.2016 · PUBLISHED 23.05.2016 


\section{BACKGROUND}

It is common for service users who suffer from substance misuse problems to claim that they need willpower to foster their recovery. Most clinicians would likely agree but point out that in addition to willpower it would be imperative to understand the process that usually leads to relapse and apply a number of skills to mitigate against it. This would be the standard Cognitive Behaviour Therapy (CBT) approach to

Ryan Kemp, Kerrie Channer, Ariana Zahn addiction. There is a growing body of experimental research which points to other processes, which facilitate the development of willpower. Our aim here is to explore the applicability of these research findings to the area of addiction treatment. In addition our aim is to challenge researchers to test the hypotheses presented here in outcome trials. While the evidence we will summarize is promising, unless this is empirically tested, it will not likely pass into clinical practice.

Self-control, synonymously referred to as selfregulation, self-discipline or willpower (Baumeister \& Tierney, 2011), is a highly adaptive ability which allows individuals to overcome habitual, default or automatic thoughts, emotions, actions or urges with standards, values and goal directed behaviour (Baumeister, Vohs, \& Tice, 2007; Gailliot et al., 2007; Baumeister, 2011). These capacities facilitate the acquisition of long-term desirable goals and altering unproductive habitual ways of being. It can appear in a negative guise, inhibiting impulses to act, while also appearing in positive behaviour, which initiates actions. Research indicates that all self-regulatory abilities draw on a single limited energy resource, and as people conduct their daily routines regulating themselves along the way, this resource suffers depletion (Baumeister et al., 2007). Depletion may be at least partially linked to glucose levels, as following a self-regulatory task blood glucose levels fall (Gailliot et al., 2007). When individuals try to make decisions in a depleted state their performance on subsequent tasks has been found to be negatively impacted (Muraven, Tice, \& Baumeister, 1998; Vohs \& Heatherton, 2000). This area of research is also linked to gratification delay experiments and follow-ups pioneered by Mischel and colleagues in the 1960s (Mischel et al., 2011).

It is therefore possible to argue that self-control can play a fundamental role in the alteration of maladaptive behaviors such as the cessation of substance use. Poor self-regulatory abilities have been linked to smoking (Fletcher, Deb, \& Sindelar, 2009), alcohol dependence (Brody \& Ge, 2001) as well as other forms of addictions (Muraven, Collins, \& Nienhaus, 2002). Research has shown that alcohol negatively affects self-control as it reduces glucose levels (Gailliot et al., 2007). This poor self-regulatory ability will present a challenge for individuals who are trying to achieve abstinence. If individuals fail to regulate themselves in line with their goals, when faced with temptation they may revert to habitual and automatic processes (Schmeichel, Vohs, \& Baumeister, 2003). Furthermore, this breakdown in self-regulatory ability may lead to secondary problems such as depression (e.g. Wenzlaff, Wegner, \& Roper, 1988), aggression (DeWall, Baumeister, Stillman, \& Gailliot, 2007) and deception (Mead, Baumeister, Gino, Schweitzer, \& Ariely, 2009).

Applying the idea of training self-control in psychiatry is not original. Various implications, models and applications have been developed for depression (Fuchs \& Rehm, 1977), anxiety (Goldfried, 1971) and addiction (Heather, Miller, \& Greeley, 1991; Hester, 1995). However, most of this was allied to behavioural models of self-control. It should also be noted that these earlier ideas about self-control have fallen out of favour with contemporary clinicians. The research which informs the current argument is in contrast based on capacity-based models. This capacity, as self-control and self-regulation, is acquired and utilized as needed. Self-control therefore has a seemingly obvious role to play in the recovery from substance addiction. To understand this further it is important to explore the mechanisms which underpin self-control and the literature which suggests that this capacity can be trained to fully understand the mechanism it plays in addiction.

\section{TRAINING THE SELF-CONTROL MUSCLE}

Baumeister and colleagues (2007) argue that self-control is analogous to a muscle. This 'strength model' is a heuristic, which proposes a way to conceptualize self-control as a limited resource, which gets drawn upon every time a decision is needed. Therefore, repeated exertions temporarily deplete the 'muscle reserve' and thus negatively affect the ability to perform subsequent tasks requiring self-control $(\mathrm{Mu}-$ raven \& Baumeister, 2000). Like a muscle, self-control gets 'tired', but unlike a muscle it rarely shows total collapse, with some studies showing that even when participants' self-control is in a depleted state, if their motivation is high they can still utilize this capacity to obtain their goals (Muraven \& Slessareva, 2003; Baumeister et al., 2007).

This 'muscle' hypothesis has been validated numerous times using the dual task paradigm whereby participants perform two seemingly unrelated self-control depleting tasks, with impaired performance consistently reported on the second task (Hagger, Wood, Stiff, \& Chatzisarantis, 2010). This depletion does not affect all processes equally. Research shows automatic processes which are independent of executive control, like rote memory, are relatively unaffected by this depletion (Schmeichel et 
al., 2003), whilst processes reliant on control by the self, such as logical reasoning and other controlled processes, decline sharply when individuals are in a state of depletion (Hagger et al., 2010).

The scientific literature behind self-control not only explains the mechanisms underpinning it but also indicates that it is possible to increase the capacity for self-control (Gailliot et al., 2007). This is vital, as the research has shown that individuals who have more self-control capacity are more likely to succeed at a range of tasks (Muraven, Collins, Shiffman, \& Paty, 2005). This allows for a translation of research from controlled experiments into the area of applied clinical science. Most simply it has been demonstrated that self-regulatory ability can be strengthened through self-control exercises (Gailliot et al., 2007). In addition, studies have also shown that even when people are in a depleted state, if they have a compelling motivational factor this can temporarily block the negative effects of depletion (Baumeister et al., 2007). This indicates that if individuals are fully committed to achieving their goals, it may serve to protect them when they experience depletion. However, whilst motivation is crucial in the utilisation of self-control, research has also conversely shown that motivation may only temporarily delay self-regulatory failure by causing people to tap into additional self-regulatory reserves (Baumeister et al., 2007). It would therefore be clinically wise to build both self-regulation and motivation.

Not only does an increased self-control capacity potentially help with addiction, but there is evidence that increased self-control is related to favorable psychological states (Tangney, Beumeister, \& Boone, 2004), positive interpersonal interactions (Schmeichel, Vohs, \& Baumeister, 2003), successes in education and work (Gailliot et al., 2007), better ability to cope with problems (Levy, 2006) and reduced criminality (Tangney et al., 2004). This is likely to prove highly useful as individuals who present to treatment with drug and alcohol problems often have multiple problems (Stark, 1992). Also, recovery is a process, which requires the rebuilding of life in a number of areas which self-control will aid (Ryan, 2013).

It is also worth reflecting on how building selfcontrol would be positive for other therapies. The National Institute for Health and Clinical Excellence (NICE) guidelines for substance misuse recommended a number of therapies, although CBT or relapse prevention was not recommended. While different therapies approach change from unique angles, all seek to equip individuals (and couples \& families) with the capacity to resist the temptation to use substances. Behavioural Couples Therapy (BCT) does this by building relationship skills which are enhanced by self-regulatory capacities (Schmeichel et al., 2003). The brief therapy, Motivational Interviewing (MI) seeks to reconnect individuals with their deep core reasons for wanting to change, while enhancing confidence and careful planning. Nonetheless those seeking to resist using substances, will still need to exercise choice and enhanced willpower. Also it is likely that early successes at resisting using drugs or alcohol will be built upon by the MI process to enhance motivation further. Contingency Management seeks to incentivize individuals against using drugs through various rewards (cash, vouchers, privileges) and it would seem, at face value at least, that enhanced self-control maps directly on to this motivational system. Although not recommended in these guidelines, Social Behaviour Network Therapy (SBNT) and the Community Reinforcement Aproach (CRA) are widely used in the field. Both combine elements of behavioural approaches with social relations building and have a very good evidence base (even if not meeting NICE standards). Perhaps here the more positive aspects of self-regulation would be seen, in that it would help initiate new behaviours and relationships, not just resist old habituated patterns.

\section{BUILDING SELF-CONTROL}

Our central argument is that adding a willpower building component into CBT for addiction would be beneficial to recovery outcomes. Cognitive Behaviour Therapy starts with behavioural analysis, which seeks to understand how particular behaviours lead to pathogenic outcomes. The approach emphasises the positive reinforcement of preferred (presumed to be healthy) behaviours. It also includes activity scheduling, rebuilding mastery and encouraging desired (pleasurable) activities (Hopko, Lejuez, Ruggiero, \& Eifert, 2003). The cognitive aspect of CBT assumes that mental health problems stem from unhealthy beliefs, which then subsequently result in inaccurate (usually negative) thought processes. These thoughts in turn result in behaviours, which have negative consequences, thereby reinforcing the underlying beliefs (Beck, Rush, Shaw, \& Emery, 1987). Notable early attempts at developing a CBT for addiction were the relapse prevention approach of Marlatt and Gordon (1985), the coping skills model of Monti, Abrams, Kadden, and Cooney (1989), while Beck and colleagues produced a classical cognitive therapy approach (Beck, Wright, Newman, \& Liese, 1993).

It is probably fair to say that contemporary CBT for addiction builds on the Marlatt and Gordon (1985) paradigm. This approach emphasizes identifying high risk situations, planning around these risks and avoiding certain cognitive traps, such as the 'rule violation effect'. While various skills are built to help prevent relapse, all rely to some extent on initiating or resisting certain behaviours. So any sort of 'coping with cravings plan' relies on the individual actually taking steps
Willpower building: a new element in relapse prevention 
Ryan Kemp,

Kerrie Channer, Ariana Zahn (such as calling a friend) if required. Clinical experience indicates that often individuals know what they are meant to do, but struggle to carry out their plans. Habituated behaviours (such as taking drugs or isolating from others) are favoured over newer behaviours (such as self-soothing techniques). Enhanced self-regulation would increase the likelihood of action in such circumstances. Similarly, not doing certain behaviours (such as frequenting high risk places) would also be enhanced. Our argument is that self-control would be additive on its own and would in addition enhance the classical elements of CBT for addiction.

There is considerable evidence that short episodes of practice on self-control tasks can result in improvements in self-regulatory ability and protect individuals from the negative effects of depletion (Hagger et al., 2010; Muraven, Baumeister, \& Tice, 1999). This is consistent with the strength model, allowing for a deep pool of resources to be available for subsequent performance on demanding self-control tasks. Self-regulation is therefore a skill, which when practiced can develop the ability to control actions. By understanding and correctly utilizing self-regulation individuals can be better equipped in reaching their goals. Individuals who practice self-regulation have shown improvements in decision making (Kelly \& Conley, 1987), maintaining relationships (Kelly \& Conley, 1987), dealing with stress (Shoda, Mischel, \& Peake, 1990) and resisting frustrations (Funder \& Block, 1989).

We propose that willpower be added to existing relapse prevention (RP) programmes and have the following core components: awareness, planning, protective habits and willpower building.

Awareness. Information and knowledge are useful starting points in relation to self-control. This allows individuals to make decisions and plan in relation to this knowledge. This is often implicit in other forms of treatment. A good example of this is the Alcoholics Anonymous (AA) acronym HALT (hungry, angry, lonely and tired) which is a useful way to remember states of being which may have a detrimental effect on willpower. At the start of the day people are most likely to be well and rested but as they go through their days regulating themselves along the way their self-control will naturally diminish.

It has been shown that individuals who believe that their efforts can benefit them in the future are less affected by depletion effects, thus demonstrating that connecting to motivation is a key variable which allows the utilization of self-regulatory ability (Baumeister et al., 2007). Furthermore, being realistic with goals so that the motivation does not dissipate is fundamental.

Planning. Anticipating and planning for times of low self-control as well as understanding self-regulation and using it effectively (conserving self-control strength) can aid the ability to attain goals (Muraven et al., 1998). When plans are made, it could be useful to consider how self-regulatory resources could be allocated to different tasks. Therefore the planning process is enhanced to reduce the decisional requirements when the tasks are carried out. This can enable the preservation of self-regulatory ability for the more critical high priority projects and goals $(\mathrm{Mu}-$ raven, Shmueli, \& Burkley, 2006).

Build protective habits. Eating well and thus ensuring that glucose levels are maintained and regularly boosted throughout the day is an important habit to build. As noted before, research has shown that the effects of lowered regulatory ability can be countered by maintaining sufficient levels of glucose (Gailliot et al., 2007). Glucose does not just come from sugars; it is also derived from most nutritional food. In addition to eating well, sleeping and resting well also replenishes reserves (Mead, Baumeister, Gino, Schweitzer, \& Ariely, 2009). Planning effectively can also help, as studies have shown that the ability to self-regulate is most depleted in the evenings (Gailliot et al., 2007), this is when thinking is strained and relapses are more likely to take place. Additionally, glucose is utilized less effectively later in the evening than it is during the day (Gailliot et al., 2007). Using humor, laughter and other positive emotions can counteract the harmful effects of self-regulatory depletion (Baumeister et al., 2007). Also rest or relaxation may help to restore self-control resources after depletion and minimize the deleterious effects of depletion on subsequent task performance (Baumeister \& Heatherton, 1996; Muraven \& Baumeister, 2000).

Exercise self-regulation. A number of ways have been suggested to build self-regulatory ability; people can train by working on everyday tasks requiring self-control (e.g. improving posture, monitoring eating habits and avoiding bad language, working on tough puzzles, not snacking on unhealthy foods, learning a skill and engaging in regular physical exercise). Fundamentally, tasks high in difficulty which require one to resist the urge to quit (Wright, Beaver, Delisi, \& Vaughn, 2008) or tasks which require the overcoming of habits while interspersed with rest, practiced for at least two weeks, are excellent for building self-control strength (Muraven, 2010). Furthermore, engaging in academic study, physical exercise and financial monitoring over a period of months have been shown to build self-control (Oaten \& Cheng, 2006).

Implicit integration of self-control in existing treatment. It is important to note that much of the work done in addiction treatment is consistent with the preserving and the building of self-regulatory ability. In relapse prevention service users are helped to identify their high-risk situations and to come up with plans to manage these contingencies, thus reducing the decisional capacity required for such tasks. Through motivational interviewing service user's natural commitment to change is strengthened, which will enable them to persevere with their recovery goals if they find themselves in depleted regulatory states. During 
treatment clients are taught a range of skills, such as decision delay, which could be seen as a self-regulatory building activity. Therefore, it may not be a question of changing what is currently being done but just labeling and re-conceptualising what is currently done as building willpower.

To concretize the above and to illustrate how we believe adding these skills into practice, we will give an example. We assume the client (a male with alcohol misuse problems) has had a classic course of CBT and the above additional training. After several months of abstinence he is invited to a wedding. As this is a high risk situation, he declines (enhanced self-control) sending a letter of explanation (enhanced behavior initiation). However soon after this he is made redundant at work, his mood drops and he loses contact with friends. He starts to crave alcohol, but enacts his plans by notifying his support structures (self-regulation), by starting to attend more AA meetings (positive behavior initiation) and when faced with very strong cravings utilizes the 'decision delay technique' (self-control). These positive actions build his confidence and he finds the AA meetings more helpful than before. He gets positive feedback from friends and family and his underlying core beliefs are altered. His motivation is also enhanced and he starts to act as a sponsor in his AA meeting. He also starts to actively seek a new job (positive behaviour initiation).

What this hypothetical example shows is that increased self-control and self-regulation not only helps in itself, it also improves the other parts of CBT for addiction. It would very difficult to separate these out in actual lived experience, as behavior is always contextual and contingent. It also shows that both relational and motivational aspects of recovery would be enhanced by increased self-regulation.

\section{CONCLUSIONS}

Our aim has been to establish a connection between experimental research and its application to clinical practice. We are confident this innovation can be delivered and is acceptable to service users. However, we have not tested whether adding 'willpower building' into relapse prevention programmes increases their effectiveness. It should also be noted that there remains some doubts about relapse prevention and CBT in addictions. As noted above, despite meta-analytic level support for relapse prevention (Irvin, Bowers, Dunn, \& Wang, 1999), the UK National Institute for Health and Clinical Excellence (NICE) guidelines were not able to recommend relapse prevention for drug disorders (NICE, 2007). Also, individual components, such as promoting coping skills have not been supported (Morgenstern \& Longabaugh, 2000). At the very least, adding another component to this form of treatment is not guaranteed to be effective.
Our argument has established that there are significant possibilities in a translation of self-control research into clinical practice. Therefore, future research should test and expand upon the area of practical applications. This should include trials which specifically test whether adding this element into treatment enhances outcomes. It should also be noted that the application of self-control enhancement will have relevance to many different disorders and this will also no doubt be explored by researchers in due course.

\section{RefERENCES}

Baumeister, R. F., \& Heatherton, T. F. (1996). Self-regulation failure: An overview. Psychological Inquiry, 7, 1-15.

Baumeister, R. F., \& Tierney, J. (2011). Willpower: Rediscovering the greatest human strength. London: Penguin.

Baumeister, R. F. (2011). Self-control the moral muscle. The Psychologist, 25, 112-115.

Baumeister, R. F., Vohs, K. D., \& Tice, D. M. (2007). The strength model of self-control. Current Directions in Psychological Science, 16, 351-355.

Beck, A. T., Rush, A. J., Shaw, B. F., \& Emery, G. (1987). Cognitive therapy of depression. New York: The Guilford Press.

Beck, A. T., Wright, F. D., Newman C. F., \& Liese, B. S. (1993). Cognitive therapy of substance abuse. New York: Guilford Press.

Brody, G. H., \& Ge, X. (2001). Linking parenting processes and self-regulation to psychological functioning and alcohol use during early adolescence. Journal of Family Psychology, 15, 82-94.

DeWall, C. N., Baumeister, R. F., Stillman, T., \& Gailliot, M. T. (2007). Violence restrained: Effects of self-regulation and its depletion on aggression. Journal of Experimental Social Psychology, 43, 62-76.

Fletcher, J. M., Deb, P., \& Sindelar, J. L. (2009). Tobacco use, taxation and self-control in adolescence $\mathrm{Na}$ tional Bureau of Economic Research Working Paper (15130). Cambridge: National Bureau of Economic Research.

Fuchs, C. Z., \& Rehm, L. P. (1977). A self-control behavior therapy program for depression. Journal of Consulting and Clinical Psychology, 45, 206-214.

Funder, D. C., \& Block, J. (1989). The role of ego-control, ego-resiliency, and IQ in delay gratification in adolescence. Journal of Personality and Social Psychology, 57, 1041-1050.

Gailliot, M. T., Baumeister, R. F., DeWall, C. N., Maner, E., Tice, D. M., Brewer, L. E., \& Schmeichel, B. J. (2007). Self-control relies on glucose as a limited energy source. Willpower is more than a metaphor. Journal of Personality and Social Psychology, 92, 325-336.
Willpower building: a new element in relapse prevention 
Goldfried, M. R. (1971). Systematic desensitization as training in self-control. Journal of Consulting and Clinical Psychology, 37, 228-234.

Hagger, M. S., Wood, C., Stiff, C., \& Chatzisarantis, N. L. (2010). Ego depletion and the strength model of self-control: a meta-analysis. Psychological Bulletin, 136, 495-525.

Heather, N., Miller, W. R., \& Greeley, J. (eds.). (1991). Self-control and the Addictive Behaviours. Australia: Pergamon Press.

Ryan Kemp,

Kerrie Channer,

Ariana Zahn

Hester, R. K. (1995). Behavioral self-control training. Washington: Allyn \& Bacon.

Hopko, D. R., Lejuez, C. W., Ruggiero, K. J., \& Eifert, G. H. (2003). Contemporary behavioral activation treatments for depression: procedures, principles, and progress. Clinical Psychology Review, 23, 699-717.

Irvin, J. E., Bowers, C. A., Dunn, M. E., \& Wang, M. C. (1999). Efficacy of relapse prevention: A meta-analytic review. Journal of Consulting and Clinical Psychology, 67, 563-570.

Kelly, E. L., \& Conley, J. J. (1987). Personality and compatibility: A prospective analysis of marital stability and marital satisfaction. Journal of Personality and Social Psychology, 52, 27-40.

Levy, N. (2006). Addiction, autonomy and ego-depletion: a response to Bennett Foddy and Julian Savulescu. Bioethics, 20, 16-20.

Marlatt, G. A., \& Gordon, J. R. (1985). Relapse prevention: Maintenance strategies in addictive behavior change. New York: Guilford.

Mead, N. L., Baumeister, R. F., Gino, F., Schweitzer, M. E., \& Ariely, D. (2009). Too tired to tell the truth: Self-control resource depletion and dishonesty. Journal of Experimental Social Psychology, 45, 594-597.

Mischel, W., Ayduk, O., Berman, M. G., Casey, B. J., Gotlib, I. H., Jonides, J., Kross, E., Teslovich, T., Wilson, N. L., Zayas, V., \& Shoda, Y. (2011). 'Willpower' over the life span: decomposing self-regulation. Social Cognitive and Affective Neuroscience, 6, 252-256.

Monti, P. M., Abrams, D. B., Kadden, R., \& Cooney, N. (1989). Treating alcohol dependence: a coping skills therapy guide. New York: Guilford.

Morgenstern, J., \& Longabaugh, R. (2000). Cognitive-behavioral treatment for alcohol dependence: A review of evidence for its hypothesized mechanisms of action. Addiction, 95, 1475-1490.

Muraven, M. (2010). Practicing self-control lowers the risk of smoking lapse. Psychology of Addicted Behaviour, 24, 446-452.

Muraven, M., \& Baumeister, R. F. (2000). Self-regulation and depletion of limited resources: Does self-control resemble a muscle? Psychological Bulletin, 126, 247-259.

Muraven, M., \& Slessareva, E. (2003). Mechanisms of Self-Control Failures: Motivation and Limited
Resources. Personality and Social Psychology Bulletin, 29, 894-906.

Muraven, M., Baumeister, R. F., \& Tice, D. M. (1999). Longitudinal improvement of self-regulation through practice: Building self-control strength through repeated exercise. The Journal of Social Psychology, 139, 446-457.

Muraven, M., Collins, R. L., \& Nienhaus, K. (2002). Self-Control and Alcohol Restraint: An Initial Application of the Self-Control Strength Model. Psychology of Addictive Behaviours, 16, 113-120.

Muraven, M., Collins, R. L., Shiffman, S., \& Paty, J. A. (2005). Daily fluctuations in self-control demands and alcohol intake. Psychology of Addictive Behaviors, 19, 140-147.

Muraven, M., Shmueli, D., \& Burkley, E. (2006). Conserving Self-Control Strength. Journal of Personality and Social Psychology, 91, 524-537.

Muraven, M., Tice, D. M., \& Baumeister, R. F. (1998). Self-control as limited resource: Regulatory depletion patterns. Journal of Personality and Social Psychology, 74, 774-789.

National Institute for Health and Clinical Excellence. (2007). Drug misuse: psychosocial interventions. London: NICE.

Ryan, F. (2013). Cognitive therapy of addiction. London: Wiley-Blackwell.

Oaten, M., \& Cheng, K. (2006). Longitudinal gains in self-regulation from regular physical exercise. British Journal of Health Psychology, 11, 717-733.

Schmeichel, B. J., Vohs, K. D., \& Baumeister, R. F. (2003). Intellectual performance and ego depletion: Role of the self in logical reasoning and other information processing. Journal of Personality and Social Psychology, 85, 33-46.

Shoda, Y., Mischel, W., \& Peake, P. K. (1990). Predicting adolescent cognitive and self regulatory compentecies from preschool delay of gratification: Identifying diagnostic conditions. Developmental Psychology, 26, 978-986.

Stark, M. J. (1992). Dropping out of substance abuse treatment: A clinically oriented review. Clinical Psychology Review, 12, 93-116.

Tangney, J. P., Baumeister, R. F., \& Boone, A. L. (2004). High self-control predicts good adjustment, less pathology, better grades, and interpersonal success. Journal of Personality, 72, 271-324.

Vohs, K. D., \& Heatherton, T. F. (2000). Self-regulatory failure: A resource-depletion approach. Psychological Science, 11, 249-254.

Wenzlaff, R. M., Wegner, D. W., \& Roper, D. W. (1988). Depression and mental control: The resurgence of unwanted negative thoughts. Journal of Personality and Social Psychology, 55, 882-892.

Wright, J., Beaver, K., Delisi, M., \& Vaughn, M. (2008). Evidence of negligible parenting influences on self-control, delinquent peers, and delinquency in a sample of twins. Justice Quarterly, 25, 544-569. 